\title{
PUBLIC RELATIONS DAN NEW MEDIA \\ (Proses Humas dalam Mengelola Instagram @universitaspertamina)
}

\section{Oleh: Sulvinajayanti}

\section{Sekolah Tinggi Agama Islam Negeri (STAIN) Parepare Email: sulvinajayanti@stainparepare.ac.id}

\begin{abstract}
PR Process in Managing Instagram @universitaspertamina. Instagram is a new media facilitate public relations practitioners in providing information to the public with the aim of providing a positive image. @ universitaspertamina is a social media account used by public relations in reaching its external public where the public target is students and academic community which has a range of usage under 40 years. @universitaspertamina is a means of public relations in shaping the image of the organization in front of the public.

In Indonesia there are 45 million active citizens using instagram. In practical terms, the instagram function is relevant to the public relations-related external public function. Instagram is a new media facilitate public relations practitioners in providing information to the public with the aim of providing a positive image. @universitaspertamina is a social media account used by public relations in reaching its external public where the public target is students and academic community which has a range of usage under 40 years. @ universitaspertamina is a means of public relations in shaping the image of the organization in front of the public.
\end{abstract}

\section{Keywords: Public Relations, New Media, Instagram}

\section{Pendahuluan}

Universitas Pertamina merupakan universitas yang berlokasi di kawasan Simprug, Jakarta Selatan. Universitas Pertamina berdiri pada tahun 2016 yang pengelolahannya berada di bawah naungan Yayasan Pertamina (Pertamina Foundation) diresmikan pada 11 Februari 2016. Universitas Pertamina menawarkan 6 fakultas dan 15 program studi strata 1. Meskipun universitas ini 
masih tergolong baru dalam dunia pendidikan, tetapi publikasi yang dilakukan oleh pihak humas yang begitu aktif dalam memanfaatkan new media bisa dikatakan mampu menarik perhatian masyarakat. Universitas Pertamina melakukan promosi dan memberikan informasi terkait perkembangan dan kegiatan yang dilakukan oleh mahasiswa dan seluruh civitas akademik melalui media sosial Facebook, Twitter, Youtube, dan Instagram. Tidak hanya media sosial, Humas Universitas Pertamina juga menggunakan line@ sebagai media chatting dalam menyebarkan informasi dan menjawab berbagai pertanyaan yang disampaikan oleh masyarakat.

Universitas Pertamina adalah salah satu universitas yang memanfaatkan fungsi Public relations dan teknologi dalam menunjang peningkatan layanan dan publikasi. Public Relations adalah fungsi manajemen yang mengevaluasi sikap publik, mengidentifikasi kebijakan dan prosedur organisasi dengan kepentingan publik dan melaksanakan program kegiatan (dan komunikasi) untuk mendapatkan pemahaman dan penerimaan publik. ${ }^{1}$ Hal ini menempatkan public relations sebagai sebuah fungsi manajemen yang mempunyai tugas untuk menjaga alur internal dan eksternal perusahaan agar tercapainya sebuah komunikasi terpadu. Public relations banyak dipraktikkan di berbagai organisasi dalam rangka menunjang manajemen untuk mencapai tujuannya secara efektif dan efisien.

Teknologi telah mengubah gagasan kita tentang media, terutama konsep media massa. Seiring perkembangan zaman yang diiringi dengan perkembangan teknologi, media massa pun ikut berevolusi. Perkembangan teknologi ini yang membuat kita tidak lagi mengandalkan cara-cara tradisional dalam mencari, memperoleh, berbagi, dan menyebarkan informasi. Media baru merupakan sebuah terminologi untuk menjelaskan konvergensi antara teknologi komunikasi digital yang terkomputerisasi serta terhubung ke jaringan. Internet merupakan revolusi komunikasi yang sangat luas dan mendalam. Dunia digital telah mengubah komunikasi didalam organisasi dan di antara organisasi dengan publiknya.

\footnotetext{
${ }^{1}$ Andini Marta, Manajemen dan Public relations, dalam http://strategikomunikasi.blogspot.com/2012/02/manajemen-dan-public-relations.html. (diakses 07 Februari 2017).
} 
Instagram adalah salah satu media baru yang menjadi pilihan public relations dalam menjalin hubungan dengan publiknya. Instagram termasuk media sosial yang unik karena mengkhususkan penggunaannya untuk berbagi foto dan video pendek. Setiap hari para pengguna instagram mengunggah sekurangkurangnya 95 juta foto dan video yang diunggah dari segala penjuru dunia. Pengguna instagram berusia di bawah 40 tahun, ini merupakan usia produktif jauh lebih muda dibandingkan dengan pengguna media sosial yang lain.

Di Indonesia terdapat 45 juta warga yang aktif menggunakan instagram. Secara praktis, fungsi instagram relevan dengan fungsi public relations eksternal yang berhubungan dengan publiknya. Instagram yang merupakan new media memudahkan praktisi public relations dalam memberikan informasi kepada publiknya dengan tujuan memberikan citra yang positif. @universitaspertamina merupakan akun media sosial yang digunakan oleh public relations dalam menjangkau public eksternalnya yang mana public sasarannya adalah mahasiswa dan civitas akademik yang mana memiliki rentang usiadibawah 40 tahun. $@$ universitaspertamina merupakan sarana public relations dalam membentuk citra organisasi didepan publiknya.

\section{Dasar Teori}

\section{Teknologi Komunikasi dan Informasi}

Teknologi komunikasi menekankan pada bagaimana suatu hasil data dapat disalurkan, disebarkan dan disampaikan ke tempat tujuan. Teknologi komunikasi berkembang cepat dengan meningkatnya perkembangan teknologi elektronika, sistem transmisi dan sistem modulasi, sehingga suatu informasi kemudian dapat disampaikan dengan cepat dan tepat. Perkembangan teknologi komunikasi kemudian menghasilkan apa yang disebut sebagai konvergensi media.

Konvergensi berasal dari bahasa Inggris "convergence", yang artinya adalah penggabungan atau pengintegrasian. Secara konsep, konvergensi merujuk pada dua hal/benda atau lebih bertemu dan bersatu dalam suatu titik. ${ }^{2}$ Konvergensi media adalah penggabungan atau pengintegrasian media-media yang

\footnotetext{
${ }^{2}$ Aris Munandar, 2006:1
} 
ada untuk digunakan dan diarahkan kedalam satu tujuan. Konsep konvergensi media ini sendiri berawal dari perkembangan teknologi komunikasi digital, bermula pada saat ditemukannya komputer, dan didorong pesat oleh konvergensi jaringan atau koeksistensi efisien telepon, video, dan paket data dalam satu jaringan, berkat adanya teknologi internet.

Konvergensi media pada dasarnya mengakomodasi perkembangan mediamedia konvensional tersebut, namun tidak secara parsial atau terpisah, melainkan secara terintegrasi dan keseluruhan, dan pada gilirannya melahirkan konsepkonsep baru dalam bidang komunikasi. Konvergensi media ini juga memaksa media-media konvensional untuk saling terintegrasi agar dapat bertahan di tengah kemajuan teknologi, dan dampak paling besar adalah menyebabkan perkembangan media konvensional kedalam bentuk digital, kemudian melahirkan apa yang disebut sebagai media sosial (social media).

Marshal McLuhan didalam bukunya yang berjudul understanding media, mengatakan bahwa: "During the mechanical ages we had extended our bodies in space. Today, after more than a century of electric technology, we have extended our central nervous system itself in a global embrace, abolishing both space and time as far as our planet is concerned. Rapidly, we approach the final phase of the extensions of man - the technological simulation of consciousness, when the creative process will be collectively and corporately extended to the whole of human society, much as we have already extended our senses and our nerves by the various media"3. McLuhan berulang kali menganalisa berbagai teknologi yang berbeda sebagai perpanjangan dari kemanusiaan atau "extension of humanity". Namun perpanjangan ini lebih bermakna sebagai amplifikasi atau akselerasi dari panca indra atau perilaku manusia yang telah ada sebelumnya.

Media dikategorikan oleh McLuhan sebagai perpanjangan dari fungsi pancaindera, khususnya indera penglihatan dan pendengaran. Media elektronik dikategorikan oleh McLuhan sebagai perpanjangan fungsi pemrosesan informasi, dan media elektronik kemudian mengambil alih fungsi manajemen informasi,

\footnotetext{
${ }^{3}$ McLuhan, Marshall. 1964. Understanding Media: The Extensions of Man. McGrawHill. h.19
} 
penyimpanan, dan penarikan informasi yang terjadi di sistem syaraf pusat dan otak manusia, seperti misalnya televisi yang merupakan perpanjangan fungsi indera pendengaran dan penglihatan, serta komputer yang merupakan perpanjangan fungsi manajemen dan pemrosesan informasi daripada otak manusia. Pada puncaknya, McLuhan membayangkan sebuah era dimana kepintaran dan kreativitas manusia akan terotomatisasi dan diterjemahkan menjadi fungsi informasi yang dilakukan oleh mesin.

\section{Komunikasi}

Komunikasi berasal dari kata latin "communicare atau communis" yang berarti sama atau menjadikan milik bersama. Bila suatu sistem atau sumber mempengaruhi yang lain dengan mengolah pemakaian isyarat-isyarat pilihan yang dapat diteruskan melalui saluran yang menghubungkan kedua belah pihak. Komunikasi merupakan proses yang menjelaskan siapa, mengatakan apa, dengan saluran apa, kepada siapa, dan dengan akibat apa atau hasil apa. ${ }^{4}$ Komunikasi antar manusia hanya bisa terjadi, jika ada seseorang yang menyampaikan pesan kepada orang lain dengan tujuan tertentu, artinya komunikasi hanya bisa terjadi kalau adanya pesan, sumber, media, penerima, dan efek. ${ }^{5}$

Sumber adalah pengirim pesan yang disebut dengan komunikator. Pesan yang disampaikan oleh sumber dapat berupa informasi, sikap, ide, opini atau pendapat. Pesan yang dimaksud dalam proses komunikasi adalah sesuatu yang disampaikan pengirim kepada penerima baik melaui tatap muka secara langsung ataupun melalui media. Media yang dimaksud disini adalah alat yang digunakan untuk memindahkan pesan dari sumber kepada penerima. Penerima merupakan pihak yang menjadi sasaran sebuah pesan dan memiliki efek yaitu perbedaan antara apa yang dipikirkan, dirasakan, dan dilakukan oleh penerima sebelum dan sesudah menerima pesan. Setiap pesan yang disampaikan oleh seorang komunikator memiliki makna.

\footnotetext{
${ }^{4}$ Harold D. Lasswell dalam Mulyana, Deddy. 2002. Metodologi Penelitian Komunikasi, Paradigma Baru ilmu Komunikasi dan Ilmu Sosial Lainnya. Bandung. PT. Remaja Rosdakarya. h.69

${ }^{5}$ Cangara, Hafied. 2011. Pengantar Ilmu Komunikasi. Jakarta: PT. Raja Grafindo Persada. H.22
} 


\section{Media Baru}

Media baru telah menyediakan konfigurasi baru bagi hubungan komunikasi. ${ }^{6}$ Media baru merupakan media yang pada saat ini sekarang sedang berkembang dan akan terus berkembang mengikuti perkembangan zaman. Media ini berkembang baik dalam segi teknologi, komunikasi, maupun informasi. Media baru pada dasarnya adalah hasil dari konvergensi dari media-media konvensional yang sudah ada sebelumnya, seperti televisi, komputer dan telepon menjadi satu media yaitu internet.

Media baru di definisikan sebagai:

a) Pengalaman tekstual baru, bentuk tekstual dan genre baru dari konsumsi media, contohnya computer games, simulasi,dan film dengan special efek.

b) Cara baru dalam merepresentasikan dunia, seperti lingkungan virtual, screenbased interactive multimedia.

c) Hubungan baru antara subjek (pengguna dan konsumen) dengan teknologi media, perubahan dalam penggunaan dan penerimaan tampilan dan media komunikasi dalam kehidupan sehari-hari.

d) Pengalaman dalam hubungan baru antara perwujudan, identitas, dan komunitas, pergeseran dalam pengalaman personal dan sosial tentang waktu, ruang, dan tempat (baik skala lokal dan global).

e) Konsepsi yang baru tentang hubungan biologisfisik dengan tantangan teknologi media, membedakan antara manusia dan tiruan, alami dan buatan, nyata dan virtual.

f) Pola baru dari organisasi dan produksi, penyesuaian dan integrasi yang lebih luas dalam budaya media, industri, ekonomi, akses, kepemilikan, dan regulasi. $^{7}$

Beberapa ciri-ciri utama yang menandai perbedaan antara media baru dengan media konvensional berdasarkan perspektif pengguna, adalah:

1. Interactivity: diindikasikan oleh rasio respon atau inisiatif dari pengguna terhadap 'tawaran' dari sumber/pengirim (pesan).

${ }^{6}$ Poster dalam David Holmes. 2005. Communication Theory: Media, Technology, and Society. London: Sage Publication. H.7

${ }^{7}$ Lister, Martin, dkk. 2009. New Media, A Critical Introduction. New York: Routledge. 
2. Social presencer (sociability), dialami oleh pengguna, sense of personal contact dengan orang lain dapat diciptakan melalui penggunaan sebuah medium.

3. Media richness: media baru dapat menjembatani adanya perbedaan kerangka referensi, mengurangi ambiguitas, memberikan isyarat-isyarat, lebih peka, dan lebih personal.

4. Autonomy, seorang pengguna merasa dapat mengendalikan isi dan menggunakannya dan bersikap independen terhadap sumber.

5. Playfulness, digunakan untuk hiburan dan kenikmatan.

6. Privacy, diasosiasikan dengan penggunaan medium dan/atau isi yang dipilih.

7. Personalization, tingkatan dimana isi dan penggunaan media bersifat personal dan unik. ${ }^{8}$

\section{Cyber Public relations}

Electronic Public relations/Online Public relations adalah inisiatif PR yang menggunakan media internet sebagai sarana publisitasnya. ${ }^{9}$ Media internet membentuk suatu trend baru dalam PR yang dikenal dengan Electronic Public relations/Online Public relations yang berfungsi untuk membangun reputasi dengan mengomunikasikan informasi dan mendengarkan permintaan pelanggan lewat media internet.

$E-P R$, jika diuraikan, $E-P R$ dapat diartikan sebagai berikut:

a. E adalah Elektronik

"E" didalam $E-P R$ adalah sama halnya dengan "E" sebelum kata mail atau commerce yang mengacu pada media elektronik internet. Mengingat popularitas dan multifungsi media internet, media ini dimanfaatkan pula oleh para pelaku PR untuk membangun merek (brand) dan memelihara kepercayaan (trust).

b. P adalah public

\footnotetext{
${ }^{8}$ McQuail ,Dennis. 2011. Teori Komunikasi Massa Edisi 6. (Penj. Putri Iva Izzati). Jakarta: Salemba Humanika

${ }^{9}$ Onggo, Bob Julius. 2004. Cyber Public Relations. Jakarta : PT. Elex Media. h.1
} 
"Public" disini mengacu bukan hanya pada publik, namun pasar konsumen. Public juga tidak hanya mengacu pada satu jenis pasar konsumen, namun pada berbagai pasar atau public audience. Media internet bisa memudahkan kita untuk menjangkau mereka dengan lebih cepat atau sebaliknya.

c. $\mathrm{R}$ adalah relations

"Relations" merupakan hubungan yang harus di pupuk antara pasar dan bisnis Anda. Itulah kunci kepercayaan pasar agar suatu bisnis berhasil. Menariknya, melalui media internet hubungan yang sifatnya one-to-one dapat dibangun dalam waktu yang cepat karena sifat internet yang interaktif. Hal ini berbeda dengan public convensional. Dalam publik konvensional kita harus menjangkau mereka dengan sifat one-to-many. Itulah sebabnya internet merupakan media yang paling ampuh dan cepat serta luas hingga saat ini.

\section{Public relations}

Public relations merupakan fungsi manajemen yang menilai sikap publik, mengidentifikasikan kebijaksanaan dan tata cara seseorang atau organisasi demi kepentingan publik, serta merencanakan dan melakukan suatu program kegiatan untuk meraih pengertian, pemahaman, dan dukungan dari publiknya". ${ }^{10}$ Defenisi dalam perspektif Islam kita dapat mengikuti defenisi yang dipakaioleh sarjana The Institute of Public relations Malaysia (IPRM) yakni: “a planned and sustained between an organization and its publics based on Islamic principles and values".(upaya terencana dan berkesinambungan untuk menciptakan dan membina komunikasi dan saling pengertian antara organisasi dan publiknya berdasarkan prinsip-prinsip Islam dan nilai-nilai Islam). ${ }^{11}$

Publik dalam public relations adalah kelompok yang harus senantiasa dihubungi dan diperhatikan, ada dua macam publik yang menjadi tujuan yaitu: publik internal dan publik eksternal. Publik internal yakni publik yang menjadi

\footnotetext{
${ }^{10}$ Cutlip,Scott M., ET AL. (2009).Effective Public Relations. Jakarta: Kencana

${ }^{11}$ Narimah dan Saodah, Public relations From The Islamic Perspective (makalah tidak diterbitkan), h.3
} 
bagian unit badan, lembaga organisasi, perusahaan seperti; pegawai/karyawan dan termasuk juga para pejabat pengambil keputusan dari lembaga itu sendiri. Publik Eksternal yakni publik umum atau orang luar dimana suatu lembaga itu berada yang harus diberi penerangan atau imformasi demi tumbuhnya goodwill dari mereka. $^{12}$

Public relations dalam arti method of communication adalah suatu rangkaian atau sistem kegiatan komunikasi. Menurut Rusadi dalam bukunya Praktek dan solusi public relations dalam situasi krisis dan pemulihan citra, kegiatan komunikasi dalam public relation berciri komunikasi yang berlangsung dua arah dan timbal balik (two way traffic comunication) antara komunikator dan komunikan dalam rangka meningkatkan pembinaan kerjasama dan pemenuhan kepentingan bersama dengan lambang-lambang yang sama (komunikasi paradigmatis). ${ }^{13}$

Fungsi Public relations officer dalam menjalankan tugas dan operasionalnya sebagai komunikator dan mediator, maupun organisator onong juga mengatakan dalam bukunya Hubungan masyarakat suatu komunikologis sebagai berikut:

a. Menunjang kegiatan manajemen dalam mencapai tujuan organisasi.

b. Membina hubungan harmonis antara organisasi dengan publik internal dan publik eksternal.

c. Menciptakan komunikasi dua arah dengan menyebarkan imformasi dari organisasi kepada publiknya dan menyalurkan opini publik kepada organisasi.

d. Melayani publik dan menasehati pimpinan organisasi demi kepentingan umum.

e. Operasionalisasi dan organisasi public relations adalah bagaimana membina hubungan harmonis antara organisasi dengan publiknya, untuk

\footnotetext{
${ }^{12}$ F. Rahmadi, Public relations Teori dan Praktek, Aplikasi dalam Badan Usaha Swasta dan Lembaga Pemerintah (Jakarta: Gramedia), h. 13

${ }^{13}$ Ruslan, Praktek dan Solusi Public relations dalam Situasi Krisis dan Pemulihan Citra, (Jakarta: Ghalia Indonesia, 1995) h. 20
} 
mencegah terjadinya rintangan psikologis, baik yang ditimbulkan dari pihak organisasi maupun dari pihak publiknnya. ${ }^{14}$

Adapun fungsi public relations alam perspektif Islam yang berdasarkan AlQur'an yaitu sebagai berikut:

a. Pemberi Peringatan

Surat Al- Fath ayat 8: "Sesungguhnya kami mengutus kamu sebagi saksi, pembawa berita gembira dan pemberi peringatan."

b. Menyebarkan dan imformasi

Surat Al- Maidah ayat 67: "Hai Rasul, sampaikanlah apa yang diturunkan kepadamu dari Tuhanmmu. Dan jika tidak kamu kerjakan (apa yang diperintahkan itu, berarti) kamu tidak menyampaikan amanat-Nya." 16

c. membangun kerja sama dan memelihara saling pengertian antara organisasi dan publik.

Surat Al- Maidah ayat 2:" Dan tolong-menolonglah kamu dalam mengerjakan kebajukan dan takwa dan janganlah tolong-menolong dalam berbuat dosa dan pelanggaran..., "17

d. memberi peringatan atau menasihati pimpinan demi kepentingan umum.

Surat Adz- Zariaat ayat 55: "Dan tetaplah memberi peringatan kerena sesungguhnya peringatan itu bebmanfaat bagi orang-orang yang beriman". 18

\section{Fact-Finding}

Dalam tahapan ini, fact-finding atau mendefinisikan masalah mencakup dalam penyelidikan dan memantau pengetahuan, opini, sikap dan perilaku pihakpihak yang terkait dengan, dipengaruhi oleh, tindakan, dan kebijakan organisasi. Pada dasarnya ini adalah fungsi intelejen organisasi , fungsi ini menyediakan

\footnotetext{
${ }^{14}$ Rusady Ruslan, Kiat dan Strategi Kampanye Public relations (Jakarta: Raja Grafindo Persada, 1997), h. 9

${ }^{15}$ Departemen Agama RI, Al- Qur'an dan terjemahan (Jakarta: Toha Putra Semarang, 1989), h 20

${ }^{16}$ Ibid, h. 6

${ }^{17}$ Ibid h. 157

${ }^{18}$ Ibid h. 862
} 
dasar untuk semua langkah dalam proses pemecahan masalah dengan menentukan "apa yang sedang terjadi saat ini?"

\section{Planning and Programming}

Setelah para praktisi public relations menemukan masalah didalam tahapan fact-finding, hal yang dilakukan selanjutnya adalah melakukan perencanaan dan pemrograman. Informasi yang dikumpulkan dalam langkah pertama digunakan untuk membuat keputusan tentang program publik, strategi tujuan, tindakan dan komunikasi, taktik, dan sasaran. Langkah ini akan mempertimbangkan temuan dari langkah dalam membuat kebijakan dan program organisasi . langkah kedua ini akan menjawab pertanyaan "Berdasarkan apa yang kita ketahui tentang situasi, apa yang harus kita lakukan atau apa yang harus kita ubah, dan apa yang harus kita katakan?"

\section{Komunikasi}

Langkah ketiga adalah mengimplementasikan program aksi dan komunikasi yang didesain untuk mencapai tujuan spesifik untuk masing-masing publik dalam rangka mencapai tujuan program. Pertanyaan dalam langkah ini adalah "Siapa yang harus melakukan dan menyampaikannya, dan kapan, di mana, dan bagaimana caranya?"

Tahapan ini juga disebut dengan tahapan penyampaian, jika penyampaiannya dilakukan secara berlainan maka dapat menimbulkan efek yang berlainan. Oleh sebab itu tahap ini sangat menentukan satu planning dan programming.

\section{Evaluation}

Tahapan evaluasi ini merupakan tahap akhir dalam proses public relations ini, dengan cara melakukan penilaian atas persiapan, implementasi, dan hasil dari program. Penyesuaian akan dilakukan sembari program diimplementasikan, dan didasarkan pada evaluasi atas umpan balik tentang bagaimana program itu berhasil atau tidak. Program akan dilanjutkan atau dihentikan setelah menjawab 
pertanyaan "Bagaimana keadaan kita sekarang atau seberapa baik langkah yang telah kita lakukan?".

\section{Pembahasan}

\section{Tahapan Fact finding}

Pada tahapan ini, pihak Universitas Pertamina hanya melakukan studi literatur dan observasi ketika membuat akun instagram @universitaspertamina. @ universitas pertamina yang dikelola oleh salah satu dosen program studi IImu Komunikasi UP selaku Manajer Humas dan Staff Humas di bidang media sosial, melakukan tahapan fact finding dengan baik. Seperti yang diungkapkan oleh pihak humas bahwa "Berdasarkan dari hasil penelitian terdahulu serta sejumlah sumber bacaan ternama menyebutkan bahwa Instagram merupakan salah satu media sosial populer masyarakat Indonesia khususnya kelompokusia remaja. Mengingat target utama UP adalah kelompok usia remaja dan dewasa, maka dibuatlah instagram @ universitas pertamina untuk memberikan infomasi kepada warga net tentang berbagai kegiatan yang dilaksanakan oleh UP.

\section{Tahapan Planning}

Media sosial UP ditujukan untuk masyarakat yang menjadi target utama UP yaitu kelompok usia remaja (siswa SMA), orangtua/wali siswa, guru sekolah, hingga mitra UP. Untuk mendukung terlaksananya fungsi-fungsi komunikasi seperti publikasi, diseminasi informasi, hingga membentuk citra Universitas Pertamina yang menjadi tugas utama Humas. Dalam melakukan tahapan ini pihak humas mengelola instagram @universitaspertamina dengan baik. Langkah yang dilakukan oleh pihak humas yaitu; "Sebelum mengunggah berita/informasi di media sosial, Humas UP melakukan perencanaan terlebih dahulu dengan menyesuaikan pada kalender atau kegiatan tertentu, mulai dari penyusunan konten hingga merancang visualisasi yang mendukung konten.”

\section{Tahapan Communicating}

Pihak Humas @universitaspertamina dalam melakukan kegiatannya dengan baik. Tahap communicating mengimplementasikan program aksi dan 
komunikasi yang didesain untuk mencapai tujuan spesifik untuk masing-masing publik dalam rangka mencapai tujuan program. Tahap communicating merupakan penyampaian informasi secara aktif kepada publik, baik publik internal maupun eksternal mengenai apa yang telah disusun dan diprogramkan. Pada proses penyampaian informasi, public relations menggunakan media dan teknik komunikasi agar dapat mencapai efek tertentu seperti yang diharapkan. ${ }^{19}$

Seperti halnya yang dilakukan pihak humas, jika konten dan poster/gambar sudah tersedia dan atas sepersetujuan dari Manajer Humas UP, maka konten dan poster/gambar diunggah di instagram untuk seterusnya setiap bulan dikaji berapa banyak follower, postingan, postingan dengan likes terbanyak, hingga pesan yang diterima oleh instagram @universitaspertamina.

\section{Tahapan Evaluating}

Evaluasi merupakan tahap akhir proses kerja public relations, diadakan untuk mengetahui apakah kegiatan humas benar-benar dilaksanakan sesuai dengan rencana. Menurut pihak humas, pada tahapan ini "evaluasi dilakukan setiap bulan untuk melihat ketercapaian humas dalam menjalankan fungsi humas seperti menyediakan berita atau materi PR, menyediakan informasi melalui pusat layanan informasi, memproduksi brosur/pamflet/leaflet/banner, melakukan aktifitas fotografi/videografi, menjalin hubungan dengan media dan mengirimkan release, rnengelola website dan sosial media. Manajer meninjau kembali tujuan, timeline, dan budget dari berbagai program yang sudah dilaksanakan maupun yang sudah berjalan." 20

\section{Penutup}

\section{Kesimpulan}

Berdasarkan pembahasan sembelumnya maka dapat disimpulkan beberapa tahapan yang dilakukan oleh pihak universitas Pertamina dalam proses humas dalam mengelola instagram @universitaspertamina diantaranya tahapan fact

\footnotetext{
${ }^{19}$ Cutlip,Scott M., ET AL. (2009).Effective Public relations. Jakarta: Kencana. h.320

${ }^{20}$ WawancaradenganHumasUniversitasPertamina 5 Oktober 2017 (via email dan chat instagram)
} 
finding, planning, communicating dan tahapan evaluating. Pada tahapan fact finding sudah dijalankan dengan baik oleh humas Universitas Pertamina dengan melakukan penelitian terlebih dahulu. Pihak humas sebelum mengunggah berita/informasi di media sosial, Humas UP melakukan perencanaan terlebih dahulu dengan menyesuaikan pada kalender atau kegiatan tertentu, mulai dari penyusunan konten hingga merancang visualisasi yang mendukung konten. Sehingga pada tahapan planning berjalan dengan baik. Tahapan communicating sudah berjalan cukup baik, dimana informasi yang diupload disesuaikan dengan jadwal kegiatan. Hal ini dibuktikan dengan melihat informasi selalu aktif dan sesuai dengan jadwal. Yang terakhir pada tahapan evaluating yang mana pihak humas melakukan evaluasi setiap bulan untuk melihat ketercapaian humas dalam menjalankan fungsi humas. Evaluasi yang dilakukan secara terjadwal merupakan langkah yang sangat baik, sehingga ada umpan balik tentang bagaimana program itu berhasil atau tidak.

\section{Daftar Pustaka}

Cangara, Hafied. 2011. Pengantar Ilmu Komunikasi. Jakarta: PT. Raja Grafindo Persada.

Cutlip, Scott M., ET AL. (2009).Effective Public Relations. Jakarta: Kencana

Departemen Agama RI. 1989. Al- Qur'an dan terjemahan. Jakarta: Toha Putra Semarang.

Holmes, David. 2005. Communication Theory: Media, Technology, and Society. London: Sage Publication.

Lister, Martin, dkk. 2009. New Media, A Critical Introduction. New York: Routledge

Marta, Andini. Manajemen dan Public relations, dalam http://strategikomunikasi.blogspot.com/2012/02/manajemen-dan-publicrelations.html. (diakses 07 Februari 2017).

McLuhan, Marshall. 1964. Understanding Media: The Extensions of Man. McGraw-Hill. 
McQuail ,Dennis. 2011. Teori Komunikasi Massa Edisi 6. (Penj. Putri Iva Izzati). Jakarta: Salemba Humanika

Mulyana, Deddy. 2002. Metodologi Penelitian Komunikasi, Paradigma Baru ilmu Komunikasi dan Ilmu Sosial Lainnya. Bandung. PT. Remaja Rosdakarya. h.69

Narimah dan Saodah, Public relations From The Islamic Perspective (makalah tidak diterbitkan).

Onggo, Bob Julius. 2004. Cyber Public Relations. Jakarta : PT. Elex Media.

Rahmadi, F. Public relations Teori dan Praktek, Aplikasi dalam Badan Usaha Swasta dan Lembaga Pemerintah. Jakarta: Gramedia.

Rusady, Ruslan. 1997. Kiat dan Strategi Kampanye Public relations. Jakarta: Raja Grafindo Persada.

Ruslan. 1995. Praktek dan Solusi Public relations dalam Situasi Krisis dan Pemulihan Citra. Jakarta: Ghalia Indonesia.

Scott M. Cutlip. 2009. Effective Public relations. Jakarta: Kencana 